Check for updates

Cite this: RSC Adv., 2019, 9, 26276

\title{
Comparison of the structure and function of a chimeric peptide modified titanium surface $\uparrow$
}

\begin{abstract}
Lei Gong, ${ }^{a}$ Hongjuan Geng, ${ }^{b}$ Xi Zhang $\mathbb{D}^{* c}$ and Ping Gao*c
Peri-implantitis is a plaque-initiating infectious disease that can be prevented by interfering with the initial bacterial attachment. At present, surface modification of implants using antimicrobial peptides can interfere with the adhesion of streptococci. In this study, the structure and function of chimeric peptides were compared to get a strategy to modify a Ti surface. Compared to the antimicrobial activity with a fragment of hBD-3, the bifunctional and multifunctional chimeric peptides retain their antimicrobial function. All peptides showed antimicrobial activity against streptococcus in biofilm and planktonic conditions. The results demonstrate significant improvement in reducing bacterial colonization onto titanium surfaces. According to the results of structure analysis, the antimicrobial activity of tyrosine in hBD3-3 was stronger than that of the alpha helix in bifunctional or multifunctional chimeric peptides. Rigid connections were proved to avoid functional domain changes due to the interaction of charges. These results indicated that the endogenous peptide fragments modifying the Ti surface could provide an environmentally friendly approach to reduce or prevent the occurrence of peri-implant diseases.
\end{abstract}

Received 6th July 2019

Accepted 12th August 2019

DOI: $10.1039 / c 9 r a 05127 a$

rsc.li/rsc-advances which can promote the stability of the implant, is mostly preferred. ${ }^{14,15}$ However, these techniques have several limitations including poor long-term adherence of the coating to the substrate material, ${ }^{16}$ nonuniformity in thickness of the deposited layer, variations in crystallinity. ${ }^{17}$ The most prominent class of target substances used for surface modification, under the biological methods, are antimicrobial peptides. ${ }^{18-20}$

As novel antimicrobial agents, antimicrobial peptides have attracted increased attention because of their resistance to the growth of bacteria, fungi and viruses. ${ }^{21-23}$ Antimicrobial peptides, according to their source, can be categorized into microbial, animal and plant origin..$^{24,25}$ Because of its endogenous and powerful antimicrobial activity, the human betadefensin-3 (hBD-3) is being studied as a multipurpose antimicrobial peptide. ${ }^{26,27}$ The known fragments of hBD-3 have antiinflammatory and membrane permeating properties. ${ }^{28}$ These fragments can be used as antimicrobial agents to synthesize bifunctional or multifunctional chimeric peptides with properties other than antimicrobial activity, and can be used to modify the surface of titanium (Ti) dental implants. ${ }^{29,30}$

By in vitro synthesis of the hBD-3 fragment as the main antimicrobial group, having specific Ti-binding peptide group, \footnotetext{
and connecting the arginine-glycine-aspartic acid (RGD) fragment with osteogenic activity, the native peptide was modified into a bifunctional or multifunctional chimeric peptide. The efficacy and effect of modification of the chimeric peptide were compared. Moreover, the feasibility of this green environmental-friendly modification method was evaluated, and an anti-infective and promoting initial stabilization strategy of implant was obtained.

${ }^{a}$ Department of Esophageal Cancer, Tianjin's Clinical Research Center for Cancer, Key Laboratory of Cancer Prevention and Therapy, National Clinical Research Center for Cancer, Tianjin Medical University Cancer Institute and Hospital, Tianjin, 300070, PR China

${ }^{b}$ Department of Stomatology, Tianjin Hospital, 406 Jiefang South Road, Hexi District, Tianjin, 300211, PR China

${ }^{c}$ School and Hospital of Stomatology, Tianjin Medical University, 12 Observatory Road, Tianjin 300070, PR China.E-mail:xizhang@tmu.edu.cn; gaoping@tmu.edu.cn $\dagger$ Electronic supplementary information (ESI) available. See DOI:
} 10.1039/c9ra05127a 


\section{Experimental}

\section{Peptide design and synthesis}

The peptides were synthesized by Sangon Biotech Co., Ltd. (Shanghai, China). The chimeric peptides were purified (up to $>95 \%$ purity) by high-performance liquid chromatography, and the purity was confirmed by mass spectrometric analysis. The basic properties and structures of the chimeric peptides were predicted by PSIPRED software, Peptide Calculator software, and peptide property calculator (http://www.pepcalc.com/). The concentration of peptides used in this study was half the minimal inhibitory concentration (MIC), unless noted otherwise. More details had been described in previous studies. ${ }^{29,30}$

\section{Preparation of Ti substrates}

The Ti substrates were prepared by evaporating pure, 300 nanometer thick Ti (99.998\% purity) films on $10 \mathrm{~mm} \times 10 \mathrm{~mm}$ silicon wafers using electron beam evaporation (Sharon Vacuum, Brockton, MA, USA). All Ti substrates were ultrasonically cleaned with acetone and $70 \%(\mathrm{v} / \mathrm{v})$ ethanol for $20 \mathrm{~min}$. Thereafter, the samples were dried in an oven at $80{ }^{\circ} \mathrm{C}$ for $15 \mathrm{~min}$ and sterilized in a steam autoclave at $120^{\circ} \mathrm{C}$ and 102.9 $\mathrm{kPa}$ for $30 \mathrm{~min}$.

\section{Raman spectroscopy}

A gold-plated microarray chip was fixed on the carrier of the microscope, and $5 \mathrm{mg}$ of the sample was evenly spread on the gold-plated microarray chip. The extended mode was selected and 10 points of the sample was randomly selected to be irradiated by the incident light with a power intensity of about 2 $\mathrm{mW}$, and Raman spectra in the wavenumber range of $1800 \mathrm{~cm}^{-1}$ to $300 \mathrm{~cm}^{-1}$ were collected with an exposure time of $10 \mathrm{~s}$. The whole process of the experiment was repeated three times.

\section{X-ray photoelectron spectroscopy (XPS) analysis}

XPS was used to analyze the elemental composition on the surface of the titanium samples. The instrument used was the X-ray photoelectron spectrometer (ESCALAB 250, USA). The excitation source was Al Ka $(1486.6 \mathrm{eV})$, and C 1s $(284.80 \mathrm{eV})$ is used as energy reference. The experiment was repeated three times.

\section{Antibacterial assays}

S. oralis (American type culture collection [ATCC] no. 9811), $S$. gordonii (ATCC no. 10558) and S. sanguinis (ATCC no. 10556) were obtained from ATCC (VA, USA). S. oralis was cultured aerobically in brain heart infusion (BHI) agar plate supplemented with $1 \%$ yeast extract for $24 \mathrm{~h}$ at $37^{\circ} \mathrm{C}$. S. gordonii and $S$. sanguinis were cultured separately in freshly prepared BHI agar plates supplemented with $5 \%$ sterile defibrinated sheep blood, $1 \%$ hemin, and $0.1 \%$ menadione, in a chamber, under anaerobic conditions of $80 \% \mathrm{~N}_{2}, 10 \% \mathrm{H}_{2}$, and $10 \% \mathrm{CO}_{2}$ for $48 \mathrm{~h}$ at $37^{\circ} \mathrm{C}$.

\section{Minimal inhibitory concentration (MIC) and minimal bactericidal concentration (MBC) measurements}

The MIC of the chimeric peptides were investigated against $S$. oralis, $S$. gordonii, and $S$. sanguinis using the standard broth microdilution method of the National Committee for Clinical Laboratory Standards (document M7-A3). The MIC was taken as the lowest concentration of peptides at which no visual growth of the bacteria was observed, and which showed no change in the optical density was detected. After treating the bacteria for $24 \mathrm{~h}$ with various concentrations of peptide, based on the MIC, $20 \mu \mathrm{L}$ of the bacterial suspension from each well of the assay plate was removed and was plated on BHI agar plates. The concentration at which more than $99.9 \%$ of the cells were inhibited was considered as the MBC.

\section{Biofilm susceptibility assay}

Biofilm formation of S. oralis, S. gordonii, and S. sanguinis was evaluated by incubating the cultures with the chimeric peptides in a 96-well microtiter plate at $37^{\circ} \mathrm{C}$ for $24 \mathrm{~h}$ and $72 \mathrm{~h}$. The resulting biofilms were fixed with $95 \%$ methanol and stained with $0.5 \%(\mathrm{w} / \mathrm{v})$ crystal violet. Thereafter, the absorbance was measured with a microplate reader at $600 \mathrm{~nm}$.

\section{Scanning electron microscopy (SEM) examination}

The Ti samples were immersed in $1 \mathrm{~mL}$ solution of the chimeric peptide (concentration, $320 \mu \mathrm{g} \mathrm{ml}{ }^{-1}$ ) for 2 hours at $4{ }^{\circ} \mathrm{C}$. The surface of the Ti samples were washed extensively with sterile phosphate-buffered saline (PBS) solution, and thereafter, with sterile deionized water. After drying, the samples were fixed and dehydrated with different concentrations of ethanol solution for 15 minutes. The morphology and distribution of the bacteria on the surface of samples were observed by scanning electron microscopy. Three different areas of each sample was scanned at a time, and the experiment was repeated three times.

\section{Transmission electron microscopy (TEM) examination}

After incubation with TBP-1-RGDS-hBD3-3 or without the peptide (control group), super-thin slice of the Ti samples were prepared for examination by TEM using previously reported methods. ${ }^{31}$ After dehydration with ethanol, the samples were cut into ultrathin slices, and stained with $2 \%$ uranyl acetate and $0.2 \%$ lead citrate before observation. The slices were viewed under an electron microscope (JEM-2100F, Japan).

\section{Results and discussion}

\section{Design of chimeric peptides}

The occurrence of peri-implant diseases is an important problem that needs to be overcome in dental field. Peri-implant diseases include peri-implant mucositis and peri-implantitis. These diseases are mainly caused by the bacteria infecting the site of osseointegration failure around the implant. Because of the characteristics of the implant structure and their way of combining with the surrounding bone tissue, the treatment outcome of peri-implant diseases, especially peri-implantitis, is 
unsatisfactory after its occurrence. Therefore, prevention of disease and promotion of early osseointegration, in the early stage of implantation, are feasible and cost-effective ways to manage peri-implant diseases. ${ }^{32,33}$

Ti-binding peptides were first discovered by Japanese researchers, and moreover, other metal-binding peptides were discovered simultaneously. ${ }^{34}$ The advantages of peptide modification of Ti surface lie in the green environmental protection of the process, it is not easy to induce dislocation of the reactive groups because of their specificity of combination. ${ }^{35}$ The first arginine (R1), fourth proline (P4) and fifth aspartate (D5) are significant residues in Ti-binding peptides that bind to $\mathrm{Ti}$ surfaces. In our previous study, we used Ti-binding peptide (RKLPDAPGMHTW) as a means to introduce antimicrobial (GKCSTRGRKCCRRKK) and osteogenesis-promoting groups (RGDS) on Ti surface. ${ }^{29,30}$ It was proved to be a simple and feasible modification strategy. Proteins perform their functions mainly through the structural stabilization of functional domains in secondary protein structures. ${ }^{36,37}$ The main challenge lies in the preservation of the functions of each group without them being affected by the structure of other groups in the design of the chimeric peptides. The three chimeric peptides designed in this study mainly used the GGG ligation to prevent secondary structure changes (Fig. 1). Flexible connections were designed to avoid functional domain changes and apply a certain degree of interaction. ${ }^{38}$ It is necessary to compare the relationship between structure and function in current design schemes in order to obtain more suitable chimeric peptides for clinical use (Fig. 2).

\section{Comparison of the structure and function of chimeric peptides}

The results obtained following the use of a software to predict the structure and analyze the properties of the chimeric peptide sequence are shown in Fig. 1. The amino acid sequence and conventional properties of the chimeric peptides are listed in Table 1. According to the in silico prediction, the synthesized chimeric peptide has a specific isoelectric point and charge number. It can be theoretically predicted that the chimeric peptide has certain antimicrobial activity, and has amphiphilicity, which aids in its antimicrobial role.

The MIC and MBC of hBD3-3 was the lowest among the three chimeric peptides evaluated. That is, hBD3-3 had the strongest antimicrobial effect on streptococcus bacteria. The bifunctional peptides had slightly reduced antimicrobial effect, while the multifunctional peptides had the least antimicrobial effect. The data are listed in Table 2. For the three chimeric peptides, $S$. oralis was more sensitive than $S$. gordonii and $S$. sanguinis.

The results of susceptibility test of biofilms were consistent with those of MIC and MBC (Fig. 4). That is, the effect of hBD3-3 on the $24 \mathrm{~h}$ and $72 \mathrm{~h}$ biofilm formation was more significant,

\section{A}

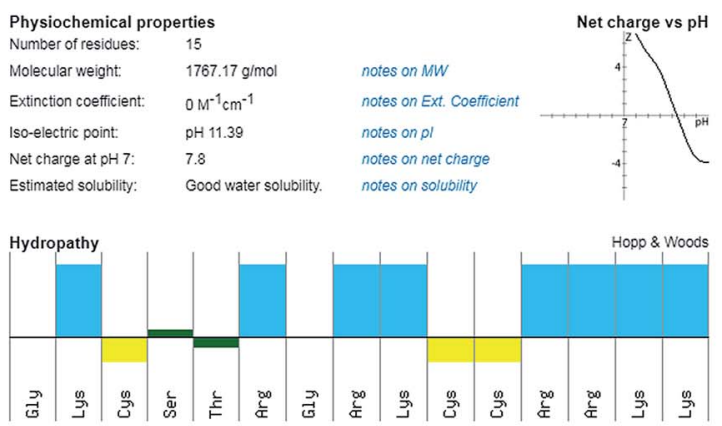

B

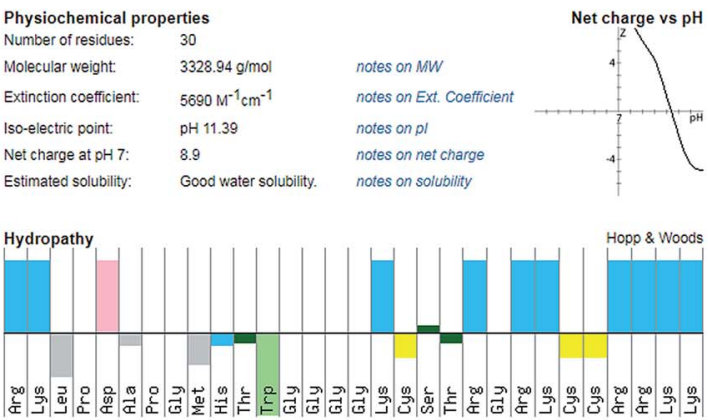

C

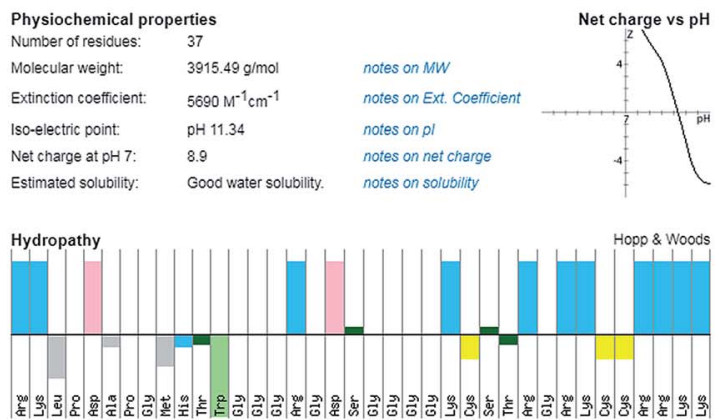

Top is hydrophilic

Bottom is hydrophobic

Color codes: Acidic Aromatic Basic Aliphatic Polar Cysteine

Fig. 1 The molecular characteristics of the peptides show amphipathic properties (top: hydrophilic, bottom: hydrophobic). (A) hBD3-3. (B) TBP1-hBD3-3. (C) TBP-1-RGDS-hBD3-3. 
A

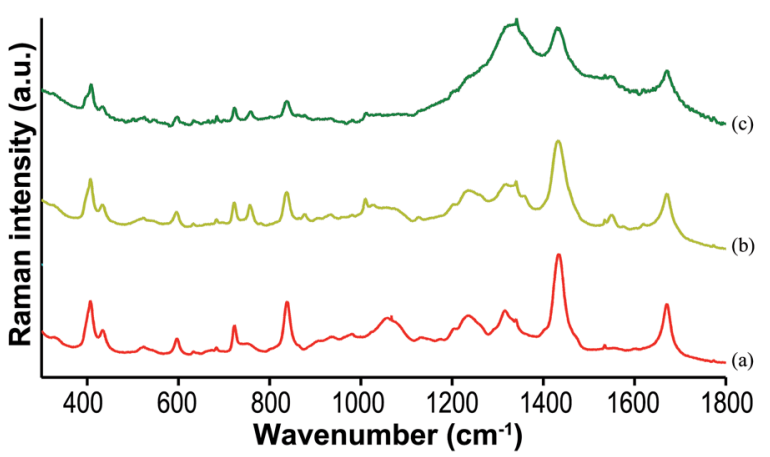

B

\begin{tabular}{ccc}
\hline Wavenumber $\left(\mathrm{cm}^{-1}\right)$ & Chemical structure & Peptide sources \\
\hline 750 & Tryptophan & $\mathrm{C}$ \\
1180 & Tyrosine & $\mathrm{A}$ \\
1240 & Random Coils & $\mathrm{A}, \mathrm{B}, \mathrm{C}$ \\
1340 & $\mathrm{a}-\mathrm{helix}$ & $\mathrm{B}, \mathrm{C}$ \\
1430 & $\mathrm{CH}_{2} \mathrm{CH}_{3}$ & $\mathrm{~A}, \mathrm{~B}, \mathrm{C}$ \\
1620 & Tyrosine & $\mathrm{A}$ \\
1666 & B-strand & $\mathrm{A}, \mathrm{B}, \mathrm{C}$ \\
\hline
\end{tabular}

Fig. 2 Raman spectra results of hBD3-3, TBP-1-hBD3-3, and TBP-1RGDS-hBD3-3. (A) Raman spectra wave results of hBD3-3 (a), TBP-1hBD3-3 (b), and TBP-1-RGDS-hBD3-3 (c). (B) Detailed structures and peptide sources (A: hBD3-3, B: TBP-1-hBD3-3, and C: TBP-1-RGDShBD3-3).

and the ratio of hBD3-3 against to biofilm formation increased from $62.4 \%$ to $76.1 \%$ at $24 \mathrm{~h}$, and from $57.6 \%$ to $79.2 \%$ at $72 \mathrm{~h}$. The index of the bifunctional chimeric peptide increased from $54 \%$ to $71.2 \%$ at $24 \mathrm{~h}$, and from $56.8 \%$ to $78.2 \%$ on $72 \mathrm{~h}$, whereas that of the multifunctional chimeric peptides increased from $49.4 \%$ to $66.9 \%$ at $24 \mathrm{~h}$, and from $48.3 \%$ to $67.1 \%$ on $72 \mathrm{~h}$. The anti-biofilm ratio was lower than that of some other antimicrobial therapy, such as photodynamic therapy. While the antimicrobial part of these chimeric peptides are from human sources, which is hard to cause the drug resistance. This is one of the advantages of antimicrobial peptides.

In terms of antimicrobial effect, hBD3-3 exhibited the strongest effect, while the other two chimeric peptides had slightly weaker antimicrobial effect in comparison. The results of MIC showed that all three chimeric peptides had antimicrobial activity, and the MIC values of the bifunctional and multifunctional peptides increased gradually. Although the MIC values of the chimeric peptides increased to a certain extent as compared with that of hBD3-3, the chimeric peptides still exhibited antimicrobial properties. The results show that the current design does not affect the functioning of the functional group, and the conjugated peptide achieves maximum effect of conjugation to the greatest extent, rather than influence.

Raman spectra showed that the structures of the three polypeptides were random coils at $1240 \mathrm{~cm}^{-1}$, the presence of $\mathrm{CH}_{2} \mathrm{CH}_{3}$ groups at $1430 \mathrm{~cm}^{-1}$, and the presence of beta folds at $1666 \mathrm{~cm}^{-1}$. Based on the current data, it is inferred that these three structures have antimicrobial activity. The tyrosine structures at $1180^{-1}$ and $1620 \mathrm{~cm}^{-1}$ peaks found in hBD3-3 were not easily found in the bifunctional and multifunctional chimeric peptides, and the alpha helix structures at $1340 \mathrm{~cm}^{-1}$ peaks in the two chimeric peptides could not be found in hBD33. Therefore, it can be inferred that tyrosine is replaced by the alpha-helix (at $1340 \mathrm{~cm}^{-1}$ of Raman spectrum) because the chimeric peptides introduce other groups and breaks the inherent secondary structure of the peptide. Comparing these three peptides, we found that tyrosine had stronger antimicrobial activity than alpha-helix. Therefore, the antimicrobial effect of chimeric peptide is not directly proportional to its length and number of structural groups, and there is a certain relationship between its function and the number of functional groups in microenvironment. ${ }^{39,40}$

XPS analysis of the binding elements' compositions of the Ti surface confirmed the presence of C 1s, O 1s (531.18 eV), Na 1s (1071.83 eV), P 2p (133.19 eV), C 12p (198.69 eV), and Ti 2p ${ }^{3}$ $(458.30 \mathrm{eV})$ as the chief components, as shown in Fig. 3. Compared with the results of the PBS-treated Ti samples, XPS analysis verify the adsorption of the chimeric peptides onto the $\mathrm{Ti}$ surface (Fig. 3).The elemental characterization of the Ti surface confirmed that the bifunctional and multifunctional peptides were effectively linked to the implant surface and played a stable role. The function of the titanium conjugates did not decrease because of the existence of other functional groups. It also shows that the modification of implant surface by Ti-conjugated peptide is a feasible and simple modification strategy.

Ti implants modified with the chimeric peptide and the streptococcus spp. on the modified surface were sampled, and the bacterial status of the modified chimeric peptide (TBP-1RGDS-hBD3-3) was visualized by SEM and TEM (Fig. 5 and ESI $\dagger$ ). According to the results of SEM, unmodified titanium surface was found to provide good growth condition for the bacterium, and moreover, the bacterial density was found to be large, with normal morphology (Fig. 5A). After modified with peptides, the surface of Ti were binded with chimeric peptides (ESI $\dagger$ ). On the chimeric peptide modified Ti surface, the bacterial density was low, and the morphology of streptococcus was found to be depressed (Fig. 5B). After modification by the chimeric peptide, the morphology of bacteria exhibited a trend

Table 1 Molecular characteristics of the synthesized peptides used in this study

\begin{tabular}{llrr}
\hline Peptide & Sequence & $\mathrm{MW}^{a}$ & $\mathrm{pI}^{a}$ \\
\hline hBD3-3 & GKCSTRGRKCCRRKK & 1767.17 & 11.39 \\
TBP-1-hBD3-3 & RKLPDAPGMHTWGGGGKCSTRGRKCCRRKK & 3328.94 & 8 \\
TBP-1-RGDS-hBD3-3 & RKLPDAPGMHTWGGGRGDSGGGGKCSTRGRKCCRRKK & 3915.49 & 8.9
\end{tabular}

${ }^{a}$ MW: molecular weight; pI: iso-electric point; Chr: net charge (http://PepCalc.com). 
Table 2 MIC and MBC values of hBD3-3, TBP-1-hBD3-3 and TBP-1-RGDS-hBD3-3 against S. oralis, S. gordonii and S. sanguinis

\begin{tabular}{|c|c|c|c|c|c|c|}
\hline \multirow[b]{2}{*}{ Bacteria } & \multicolumn{3}{|c|}{$\operatorname{MIC}\left(\mu \mathrm{g} \mathrm{ml} \mathrm{m}^{-1}\right)$} & \multicolumn{3}{|c|}{$\operatorname{MBC}\left(\mu \mathrm{g} \mathrm{ml}{ }^{-1}\right)$} \\
\hline & hBD3-3 & TBP-1-hBD3-3 & TBP-1-RGDS-hBD3-3 & hBD3-3 & TBP-1-hBD3-3 & TBP-1-RGDS-hBD3-3 \\
\hline S. oralis & 200 & 320 & 600 & 350 & 640 & 1000 \\
\hline S. sanguinis & 250 & 500 & 850 & 500 & 800 & 1200 \\
\hline S. gordonii & 300 & 500 & 850 & 600 & 850 & 1300 \\
\hline
\end{tabular}
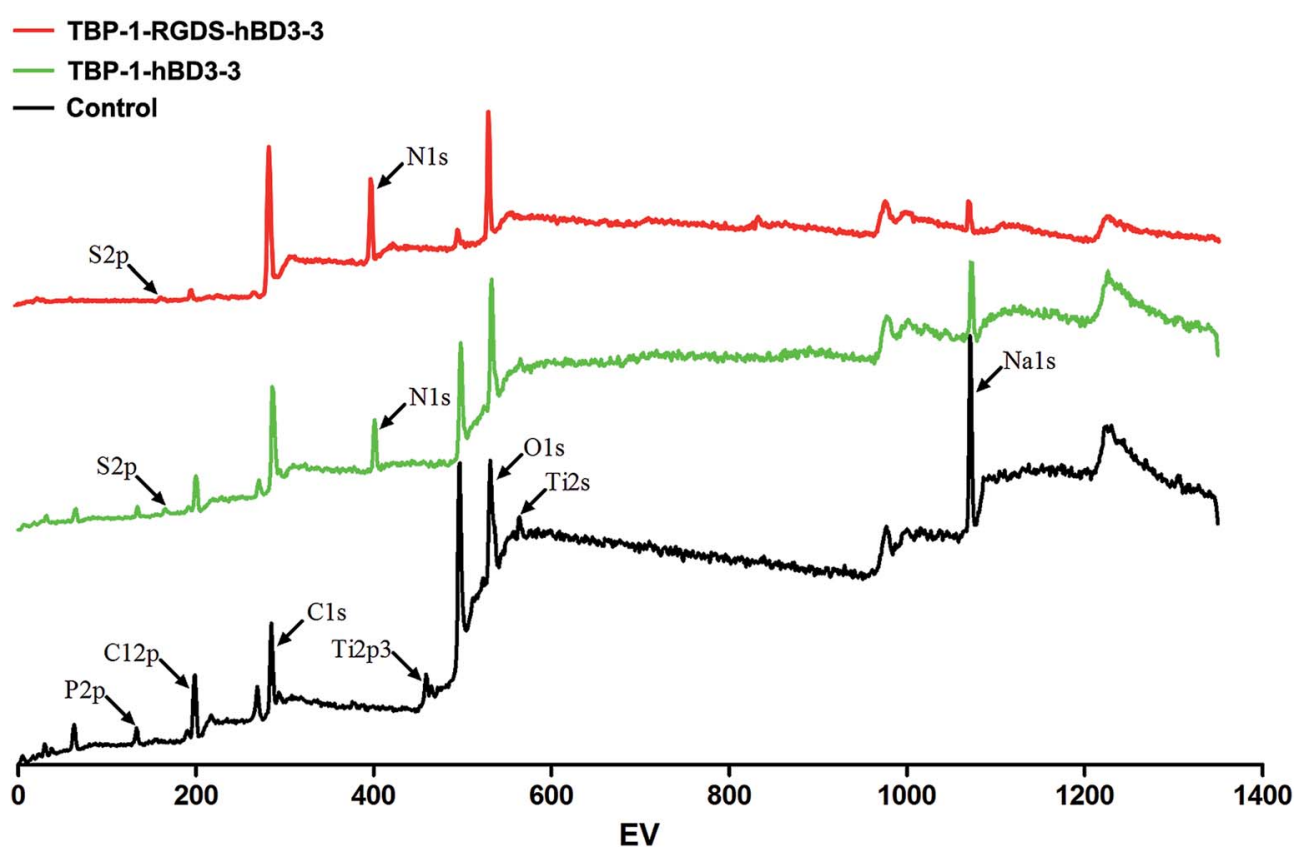

Fig. 3 XPS wide-scan spectra of Ti surfaces: Ti treated with PBS (control) and Ti treated with TBP-1-hBD3-3 or TBP-1-RGDS-hBD3-3 dissolved in PBS. Elemental composition of Ti disc surfaces with or without chimeric peptides treatment, as determined via XPS.

of cell wall destruction and leakage of intracellular content (Fig. 5C), suggesting the mechanism of action of the antimicrobial groups. In Raman spectroscopic structure analysis, alpha-helix and beta-fold structures were found in multifunctional chimeric peptides, which also confirmed the mechanism of action of antimicrobial peptides. Although these antimicrobial peptides caused leakage of intracellular content, the results of cytotoxicity experiments showed that the three chimeric peptides exhibited no significant cytotoxicity toward MC3T3-E1 cells. $^{29,30}$
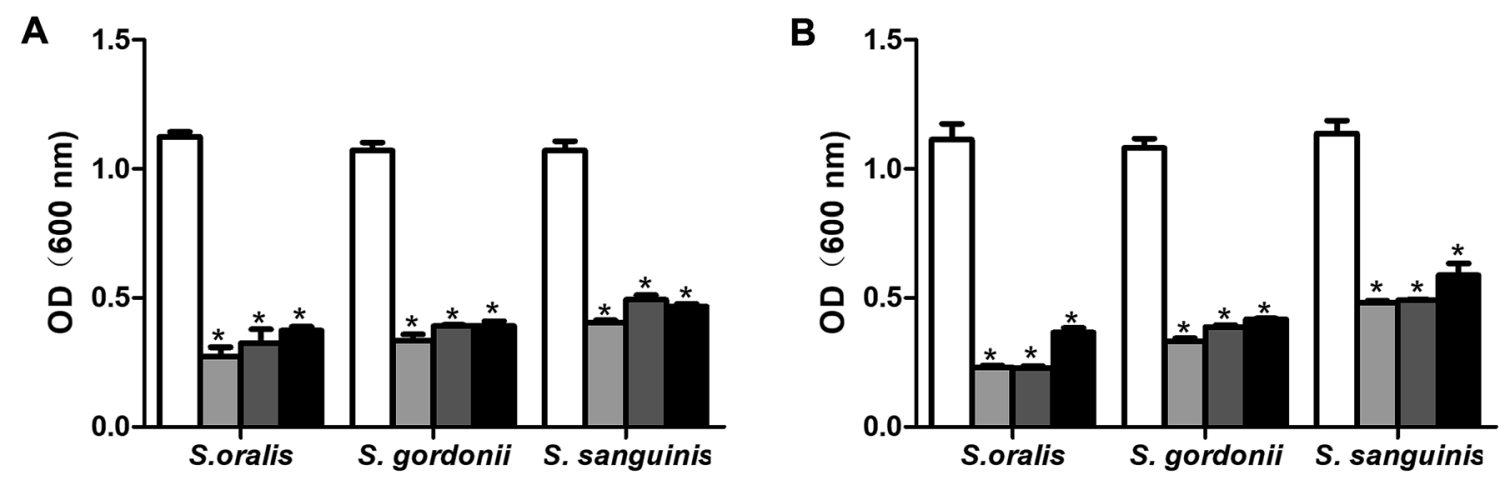

$\square$ BHI $\square$ hBD3-3 $\square$ TBP-1-hBD3-3 $\square$ TBP-1-RGDS-hBD3-3

Fig. 4 Antibacterial effects of hBD3-3, TBP-1-hBD3-3, and TBP-1-RGDS-hBD3-3 against single-species (S. oralis, S. gordonii or S. sanguinis) biofilms. Biofilms treated with the three peptides (1/2 MIC) were incubated for $24 \mathrm{~h}(\mathrm{~A})$ or $72 \mathrm{~h}(\mathrm{~B})$. Data are shown as the mean $\pm \mathrm{SEM} ; n=3$. $* P<$ 0.01 compared with the control groups. 
A

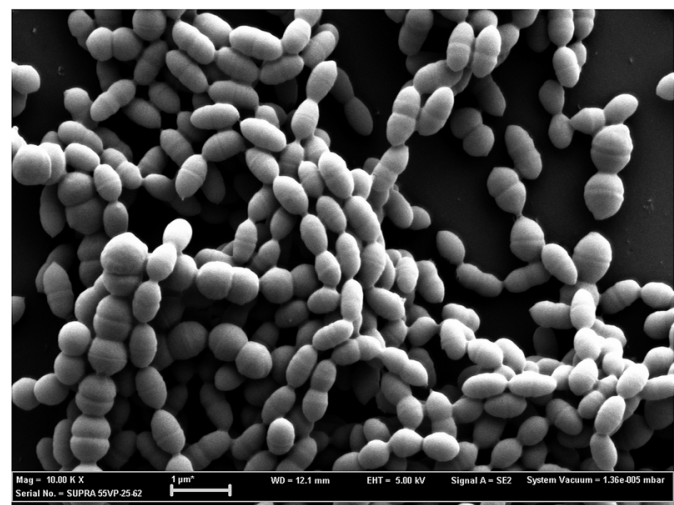

B

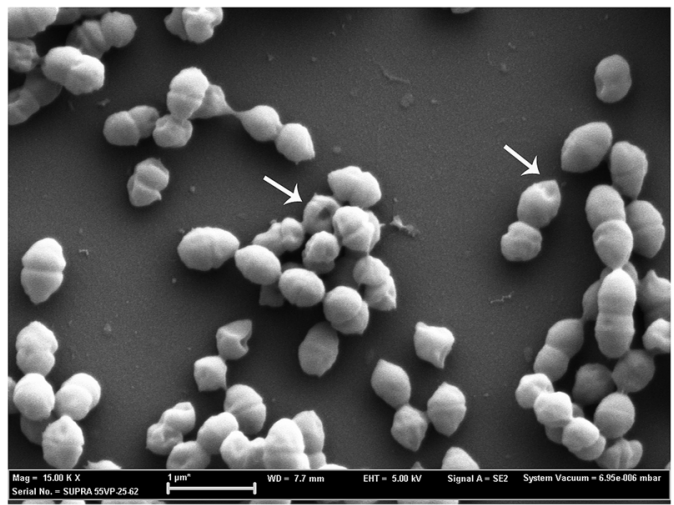

C

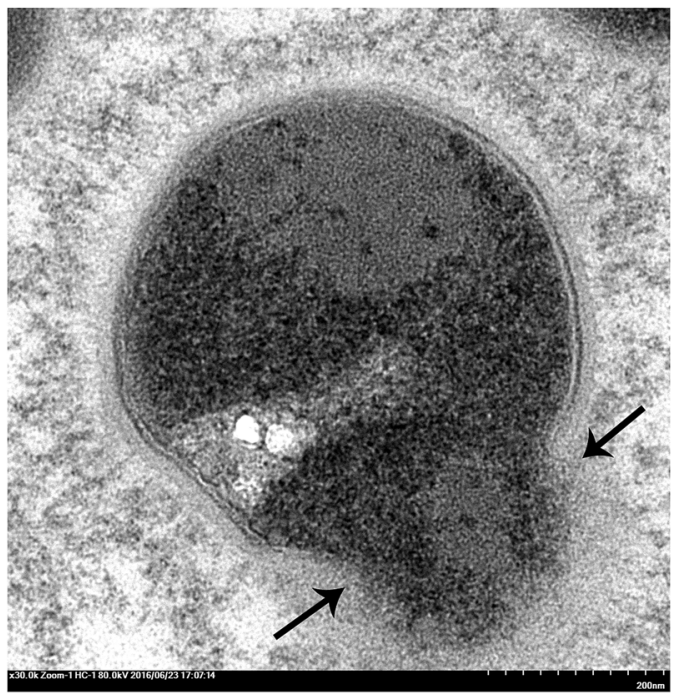

Fig. 5 (A) SEM images of S. gordonii biofilms formation for 24 h. (B) SEM images of S. gordonii biofilms that were treated with TBP-1-RGDShBD3-3 at $320 \mu \mathrm{g} \mathrm{mL}^{-1}$ for $24 \mathrm{~h}$. (C) TEM micrographs of the inner structures of S. gordonii that were treated with TBP-1-RGDS-hBD3-3 at 320 $\mu \mathrm{g} \mathrm{mL} \mathrm{L}^{-1}$ for $12 \mathrm{~h}$. White or black arrows: disruption of the cell membrane and release of cellular contents.

Our previous studies have shown that chimeric peptides can inhibit the formation of biofilm by inhibiting gene expression. ${ }^{29,30}$ However, more extensive studies have not yet been undertaken to clarify the same. At the same time, the stability of antimicrobial peptide modified titanium surfaces and the antiinflammatory effects will be confirmed in vivo experiments. Our future research will focus on optimizing the length of the chimeric peptides, to maximize functional group retention and shortening their action length in order to achieve the possibility of clinical application.

\section{Conclusions}

In summary, the surface modification of implants can be accomplished by ligation with titanium-bound peptide, with hBD3 fragment as the antimicrobial group, RGD fragment as ligation, to synthesize the multi-functional chimeric peptide. Simultaneously, the results of $72 \mathrm{~h}$ biofilm resistance showed that the chimeric peptides could disrupt the formation of biofilm by inhibiting the early attachment bacteria to the implant surface. This modification method provides an effective strategy for the prevention of peri-implantitis. Our further results about the chimeric peptides against $S$. gordonii, Fusobacterium nucleatum, and Porphyromonas gingivalis showed that the peptides had more antibacterial activity against mixed bacteria than single bacteria. However, the current research is limited to the results of the antimicrobial activity of hBD3 fragment. The mechanism of action of the chimeric peptide needs to be explored in future.

\section{Conflicts of interest}

There are no conflicts of interest relating to this work.

\section{Acknowledgements}

The work supported by the National Natural Science Foundation of China (Grant No. 81501798 and Grant No. 81501994), Tianjin Natural Science Foundation (18JCYBJC95700), Tianjin Medical University Cancer Institute and Hospital Clinical Trials 
Foundation (C1711) and Wu Jieping Medical Foundation (320.2730.1886.).

\section{References}

1 T. Berglundh, G. Armitage, M. G. Araujo, G. Avila-Ortiz, J. Blanco, P. M. Camargo, S. Chen, D. Cochran, J. Derks, E. Figuero, C. H. F. Hammerle, L. J. A. Heitz-Mayfield, G. Huynh-Ba, V. Iacono, K. T. Koo, F. Lambert, L. McCauley, M. Quirynen, S. Renvert, G. E. Salvi, F. Schwarz, D. Tarnow, C. Tomasi, H. L. Wang and N. Zitzmann, J. Periodontol., 2018, 89(1), S313-S318.

2 F. Schwarz, J. Derks, A. Monje and H. L. Wang, J. Periodontol., 2018, 89(1), S267-S290.

3 K. Robertson, T. Shahbazian and S. MacLeod, Dent. Clin. North Am., 2015, 59, 329-343.

4 B. Klinge, A. Klinge, K. Bertl and A. Stavropoulos, Eur. J. Oral Sci., 2018, 126(1), 88-94.

5 O. Carcuac, J. Derks, I. Abrahamsson, J. L. Wennstrom, M. Petzold and T. Berglundh, J. Clin. Periodontol., 2017, 44, 1294-1303.

6 L. J. A. Heitz-Mayfield, G. E. Salvi, A. Mombelli, P. J. Loup, F. Heitz, E. Kruger and N. P. Lang, Clin. Oral Implant. Res., 2018, 29, 1-6.

7 J. Nart, R. Pons, C. Valles, A. Esmatges, I. Sanz-Martin and A. Monje, Clin. Oral Investig., 2019, DOI: 10.1007/s00784019-02943-8.

8 O. Carcuac, I. Abrahamsson, G. Charalampakis and T. Berglundh, J. Clin. Periodontol., 2015, 42, 196-203.

9 P. Vigano, K. A. Apaza Alccayhuaman, S. Sakuma, Y. Amari, F. Bengazi and D. Botticelli, J. Investig. Clin. Dent., 2019, 10, e12378.

10 X. Wu, X. Chen, W. Mi, T. Wu, Q. Gu and H. Huang, Biosci. Rep., 2017, 37, BSR20170768.

11 S. Karthigeyan, A. J. Ravindran, R. T. R. Bhat, M. N. Nageshwarao, S. V. Murugesan and V. Angamuthu, J. Pharm. BioAllied Sci., 2019, 11, S131-S134.

12 A. Dehghanghadikolaei and B. Fotovvati, Materials, 2019, 12, E1795.

13 J. Vishnu, V. K. Manivasagam, V. Gopal, C. B. Garcia, P. Hameed, G. Manivasagam and T. J. Webster, Nanomedicine, 2019, 102016, DOI: 10.1016/ j.nano.2019.102016.

14 A. Jemat, M. J. Ghazali, M. Razali and Y. Otsuka, BioMed Res. Int., 2015, 2015, 791725.

15 Y. Hao, X. Huang, X. Zhou, M. Li, B. Ren, X. Peng and L. Cheng, Int. J. Mol. Sci., 2018, 19, E3157.

16 F. M. He, G. L. Yang, Y. N. Li, X. X. Wang and S. F. Zhao, Int. J. Oral Maxillofac. Surg., 2009, 38, 677-681.

17 C. J. Tredwin, G. Georgiou, H. W. Kim and J. C. Knowles, Dent. Mater., 2013, 29, 521-529.
18 J. J. Swartjes, P. K. Sharma, T. G. van Kooten, H. C. van der Mei, M. Mahmoudi, H. J. Busscher and E. T. Rochford, Curr. Med. Chem., 2015, 22, 2116-2129.

19 H. Chouirfa, H. Bouloussa, V. Migonney and C. FalentinDaudre, Acta Biomater., 2019, 83, 37-54.

20 Y. He, C. Mu, X. Shen, Z. Yuan, J. Liu, W. Chen, C. Lin, B. Tao, B. Liu and K. Cai, Acta Biomater., 2018, 80, 412-424.

21 D. Parai, P. Dey and S. K. Mukherjee, Curr. Drug Discovery Technol., 2019, DOI: 10.2174/1570163816666190620114338.

22 E. F. Haney, S. K. Straus and R. E. W. Hancock, Front. Chem., 2019, 7, 43.

23 Z. Amso and Z. Hayouka, Chem. Commun., 2019, 55, 20072014.

24 S. Spanig and D. Heider, BioData Min., 2019, $12,7$.

25 P. Singh, A. Garg, S. Pandit, V. Mokkapati and I. Mijakovic, Nanomaterials, 2018, 8, E1009.

26 A. Bayer, J. Lammel, M. Tohidnezhad, S. Lippross, P. Behrendt, T. Kluter, T. Pufe, J. Cremer, H. Jahr, F. Rademacher, R. Glaser and J. Harder, Mediators Inflammation, 2017, 2017, 6157491.

27 T. H. Lee, K. N. Hall and M. I. Aguilar, Curr. Top. Med. Chem., 2016, 16, 25-39.

28 J. Y. Lee, J. S. Suh, J. M. Kim, J. H. Kim, H. J. Park, Y. J. Park and C. P. Chung, Int. J. Nanomed., 2015, 10, 5423-5434.

29 X. Zhang, H. Geng, L. Gong, Q. Zhang, H. Li, X. Zhang, Y. Wang and P. Gao, Int. J. Nanomed., 2018, 13, 5361-5375.

30 H. Geng, Y. Yuan, A. Adayi, X. Zhang, X. Song, L. Gong, X. Zhang and P. Gao, Mater. Sci. Eng., C, 2018, 82, 141-154. 31 L. Mei, Z. Lu, W. Zhang, Z. Wu, X. Zhang, Y. Wang, Y. Luo, C. Li and Y. Jia, Biomaterials, 2013, 34, 10328-10337.

32 Z. Yuan, B. Tao, Y. He, J. Liu, C. Lin, X. Shen, Y. Ding, Y. Yu, C. Mu, P. Liu and K. Cai, Biomaterials, 2019, 217, 119290.

33 B. Zhao, H. C. van der Mei, G. Subbiahdoss, J. de Vries, M. Rustema-Abbing, R. Kuijer, H. J. Busscher and Y. Ren, Dent. Mater., 2014, 30, 716-727.

34 K. Sano, H. Sasaki and K. Shiba, Langmuir, 2005, 21, 30903095.

35 Y. Suzuki, H. Shindo and T. Asakura, J. Phys. Chem. B, 2016, 120, 4600-4607.

36 K. Kundert and T. Kortemme, Biol. Chem., 2019, 400, 275288.

37 I. Rehman and S. Botelho, in StatPearls, Treasure Island (FL), 2019.

38 X. Chen, J. L. Zaro and W. C. Shen, Adv. Drug Delivery Rev., 2013, 65, 1357-1369.

39 R. W. Newberry and R. T. Raines, ACS Chem. Biol., 2019, 14, 1677-1686.

40 D. F. Gauto, L. F. Estrozi, C. D. Schwieters, G. Effantin, P. Macek, R. Sounier, A. C. Sivertsen, E. Schmidt, R. Kerfah, G. Mas, J. P. Colletier, P. Guntert, A. Favier, G. Schoehn, P. Schanda and J. Boisbouvier, Nat. Commun., 2019, 10, 2697. 